\title{
Four seasons in one day
}

Today I am a hero.

\section{Today I am a coward.}

Today I drive for the first time to a small community, one suffering from such a dearth of doctors that patients apologize when presenting for care.

Doc, I'm sorry for bothering you on such a nice Sunday, but we're worried because our baby girl had a big fever yesterday.

The dawn breaks early and my car glides along the verdant routes. The highway is quick and carefree, slipping softly under the wheels like blades of grass in the wind.

I examine the little infant with blooming emerald eyes. Afebrile. Morbilliform rash. Calm as a lamb. I reassure the parents. They look at me hopefully.

The sun glistens intently, its shine an easy gold. The road twists and turns, lazily absorbing my car in its mountainous villi. I feel at one with the trek, at one with the potential of things to come.

I part the young man's wheat blond hair and glue together the laceration. "That's it?" he roars in astonishment. "That's it."

Thoughts are broken by the crackle of thunder. Clouds converge in a grey embolus and lodge in my windshield. The rain begins to sprinkle, then turns angry, forceful. I release the headlights, trying to pierce the darkness. The gloom accumulates. I fatigue.

I drag my legs into the acute treatment area. The logging supervisor lies clutching the chest of his bright red lumber jacket as I note the worrisome blood results and ST-segment elevations. "Let's start thrombolytics and try to penetrate this clot." I hear my words as a melancholy echo.

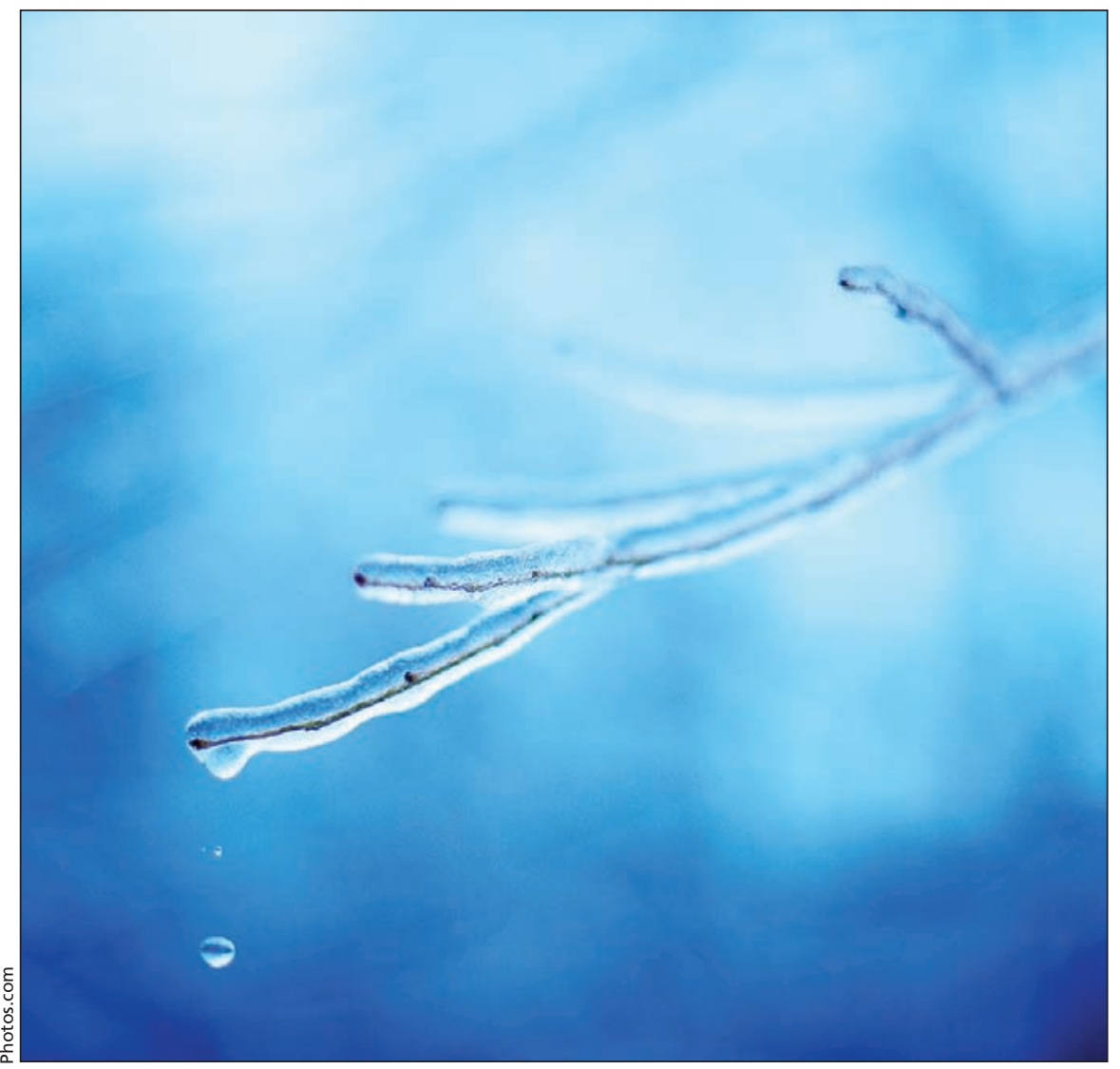

Soon upon me are unfamiliar roads, and the landscape becomes grey and sparse. I lurch up the leafless paved slope in colicky bursts. There are few other cars, distant specks. The treading below me turns more precarious as the visibility waffles. Cluster bombs of snow explode relentlessly around me, permitting only momentary glimpses of the treacherous path of slush and ice lying ahead. My car skids, control is an illusion.

The ambulance speeds into the emergency room bay, sirens wailing despite the late hour. Attendants wheel in a blanket-cloaked cachectic elderly man; "Can't breathe," he whispers through blue lips encircled by the frozen forest of his icy white beard.

The barrage dampens down. The road re-emerges. The sun triumphantly swings into view and vanquishes all cloud. I remove my sweater, seek my sunglasses and listen thoughtlessly to the purring of the overworked engine. Pulling into town, I find my accommodations and disappear into a dreamsoaked sleep.

The night is long but finite. I shuffle, exhausted, out of the hospital to again greet the knowing dawn.

Four seasons in one day to arrive.

Four seasons on arrival.

\section{Eric Cadesky MD CM}

Family physician

Clinical instructor

University of British Columbia

Vancouver, BC

This article is a metaphorical reflection on the polyvalence of medicine. Anonymity has been kept for all descriptions of clinical encounters. 